\title{
Technology-based regional development strategies and the emergence of technological communities: a case study of HSIP, Taiwan
}

\author{
Tai-Shan $\mathrm{Hu}^{\mathrm{a}, *}$, Chien-Yuan Lin ${ }^{\mathrm{b}}$, Su-Li Chang ${ }^{\mathrm{c}}$ \\ ${ }^{a}$ Department of Architecture and Urban Planning, Chung-Hua University, No. 707, Sec. 2, WuFu Road, Hsinchu City 300, Taiwan \\ ${ }^{\mathrm{b}}$ Graduate Institute of Building and Planning, National Taiwan University, No.1, Sec. 4, Roosevelt Road, Taipei 106, Taiwan \\ ${ }^{\mathrm{c}}$ Graduate Institute of Technology Management, Chung-Hua University, Hsinchu, \\ Taiwan. No. 707, Sec. 2, WuFu Road, Hsinchu City, 300 Taiwan
}

\begin{abstract}
Less-developed countries always lack well-developed industrial clusters, and nurturing such clusters is essential to their economic development, especially for technology-based industries. Consequently, location specific cluster formation should be promoted, including efficient technological infrastructure, mature innovation-production interaction, and competitive advantages. These factors have a positive accumulative effect on the selected district, and firms in the district compete for these resources through spatial proximity, a focus on certain technologies and technological infrastructure. To establish mature clusters, the Taiwanese government has aggressively developed Science Parks during the past two decades. This study applies this concept to analyze the interaction between agents and the formation of innovation clusters in the Hsinchu district, the location of the first Science Park in Taiwan.
\end{abstract}

(C) 2003 Elsevier Ltd. All rights reserved.

Keywords: Hsinchu Science-Based Industrial Park; Proximity; Cluster; Technological infrastructure

\section{Introduction}

Since the end of the 1980s, the development of the knowledge-based economy, globalization, and international competitive pressure has increased the importance of innovation in local economies (Camagni, 1995; Feldman, 1994; Malmberg, 1997; Porter, 1990; Ritsila, 1999; Storper, 1995). Simultaneously, globalization is increasing distinct local differences arising from local capabilities and environments. Under the globalized international labor system, the mid-1990s saw a new development model involving Taiwan, China and the United States replaced the previous model involving the United States, Japan and Taiwan that had dominated during the 1970s and 1980s. Although Taiwan retains competitive advantages over China in the vertical division of technology in the new

\footnotetext{
* Corresponding author. Tel. + 886-3-518-6692; fax: + 886-3-537-2832.

E-mail addresses: hts@chu.edu.tw (T.-S. Hu), cylin@ccms.ntu.edu.tw (C.-Y. Lin), suli@mail.yust.edu.tw (S.-L. Chang).
}

model, its time lead has reduced significantly. ${ }^{1}$ Therefore, to maintain the international competitiveness of Taiwan, the establishment of a business friendly environment and local innovation clusters, namely, the creation of an environment to enhance local innovative capabilities, is a pressing task.

Empirical studies during the past 10 years stressed the role of "endogenous growth mechanism" in local development, as well as influences such as local entrepreneurship, social network, synergy elements, dynamic learning process, and so on. The work reveal a need to further study the role of innovative activities, their effect on boosting local development and growth, and the agglomeration of milieu. Empirical research on innovation is focused on knowledge spillover and spatial proximity (Acs and Audretsch, 1988; Audretsch, 1998; Glaeser et al., 1992; Saxenian, 1994;

\footnotetext{
${ }^{1}$ According to a survey result published by the Wintel Survey Center, $78 \%$ of investors investing in Taiwan thought that the years 2002-2003 will represent the peak of capital flows from Taiwan into China. Moreover, the same investors expected that the Chinese information technology industry would surpass that of Taiwan after 5 years.
} 
Storper, 1995), knowledge flow and the limits of geographical dispersal (Audretsch and Feldman, 1996), collective learning process (Maillat, 1998), learning process and the stickiness of certain forms of knowledge (Markusen, 1996), and untraded dependencies (Freeman, 1991). However, spatial proximity does not necessarily guarantee learning initiation (Malmberg, 1997). Companies require proximity to competitors, suppliers, consumers, and technological infrastructure to improve their competitiveness through learning (Porter, 1998). Previous research on Taiwan included applying the concept of learning regions to discuss the formation of the industrial corridor in Northern Taiwan (Hsu, 1998), combining the concepts of learning region and regional dynamic competitive advantages to analyze the industrial system and geographic structure of the Hsinchu district (Yang, 1999), and examining how spin-offs caused the geographic concentration of high-tech industries in the Hsinchu district (Kung, 1999). Studies by Taiwanese or non-Taiwanese scholars share a common tendency of stressing the role of spatial proximity in enhancing interactions among companies, the establishment of nontrading dependencies, and agglomeration in a single locality. However, some researchers have presented different views. For example, Porter (1990) believed that geographic clustering intensifies competition, and thus increases interaction intensity within the local integral system. That is, the clustering phenomenon involves a mechanism which can maintain competitiveness among companies and facilitate information flow and exchange. Hart and Simmie (1997) used case studies to demonstrate that, although innovative companies tend to agglomerate in certain areas, owing to their competition to acquire capital and release new products, such companies may not enjoy close relationships, and may not even form an innovative production network.

Since SMEs do not have the same advantages as large enterprises in pursuing innovation, the question arises of how such companies can compete and gain knowledge. Based on the hypothesis of this study, namely that local production networks are the basis of innovation, knowledge spillover from academic institutions or research and development $(\mathrm{R} \& \mathrm{D})$ conducted by other companies is the key to obtaining knowledge for SMEs. While high-tech industries have long used employee stock distributions to enhance employee loyalty, the effectiveness of this method for agents with specific economic knowledge is uncertain. Another important question is whether this is one of the resources that companies clustering in certain localities compete to acquire, especially since they can boost their profits by accelerating new product release. Because few work have studied these particular research questions, this work hypothesizes that when companies cluster in certain localities, their interactions inevitably involved competition for specific local resources. These resources include agents with endowments of new economic knowledge, technology professionals, knowledge and information, production markets, and even partners. Although local agents sometimes collaborate, whether this collaboration remains essential to competition is uncertain. This study attempts to use this perspective to examine the interactions among local agents and the development of an innovative environment. Moreover, this study also uses the Hsinchu district, where the Taiwanese high-tech industry is concentrated, as a case study for investigating the developmental characteristics of an innovative environment.

This paper will first describe the technology-based regional development strategies in Taiwan. Then, the research method and scope will be introduced. In addition to analyzing, the developmental characteristics of the Hsinchu Science Park and the surrounding areas, the survey results are discussed. Finally, we will summarize the findings of this work and offer conclusions.

\section{Development strategies of Science/Technology Park (STP) in Taiwan}

Asian countries frequently follow policies of using strategic investments, typically by central government, to create technology-based clusters or cities to serve as growth engines for their respective regions. Owing to substantial government investment, as well as rent and tax incentives, Taiwanese STP such as the Hsinchu Sciencebased Industrial Park (HSIP), established in 1980, and the Tainan Science-based Industrial Park (TSIP), established in 1995, have become closely integrated with regional industries and local development. Thus, high-tech and innovative firms generally remain concentrated in specific locations, use shared facilities, and enjoy common economic benefits. These specific characteristics can be transformed into regional development. From this perspective, STP can be an effective tool for integrating industry and regional development. Comparing the development of Hsinchu Science City in Taiwan with the planned development of Tsukuba Science City in Japan and Taedok Science Town in Korea reveals some unique experiences in Taiwan in that the government-led projects have successfully stimulated the regional, and even national, emergence of innovation systems and economic development (Lin, 1997).

The functions assigned to Parks and the actual activities conducted in them differ according to different regional developmental goals. Primarily, an STP offers place for nurturing SMEs or new start-ups, as well as for firms to conduct $\mathrm{R} \& \mathrm{D}$ or technology transfers and produce or assemble high-tech products. According to developmental goals, functions, relationships with regional development, and development methods and management, the orientation of STP can be categorized into three types, namely, innovation/incubation-oriented (I\&IO), R\&D-oriented (R\&DO), and production-oriented (PO). I\&IO parks 
primarily endeavor to utilize new technology to stimulate industrial innovation. Such parks create new industrial foundations to attract R\&D personnel from universities and research institutes to apply the results of basic research. New technology-based firms (NTBFs) are created during this process. Generally, this type of park is located around universities or research institutes.

Second, R\&DO parks attempt to develop industrial technologies and promote industrial upgrading. These parks also aim at attracting regional firms and adopting measures to encourage firms to participate in $R \& D$. Most $R \& D O$ parks are also located around universities or research institutes. Consequently, R\&DO parks can access spillover from knowledge-based activities and existing technological infrastructures in the area. Furthermore, such parks help to attract knowledge actors.

Third, PO parks attempt to establish regional industries and promote economic growth. These parks generally produce or assembly technological products. The items produced in these parks share several characteristics: (1) large market potential, (2) wide use, (3) high added value, and (4) technology intensive. The above product characteristics distinguish Science Park production from that of most industrial zones in Taiwan. Based on the special characteristics of different areas, Taiwan can be divided into urban and community areas, and the following developmental strategies can be proposed for STPs in the Taiwan area (Fig. 1).

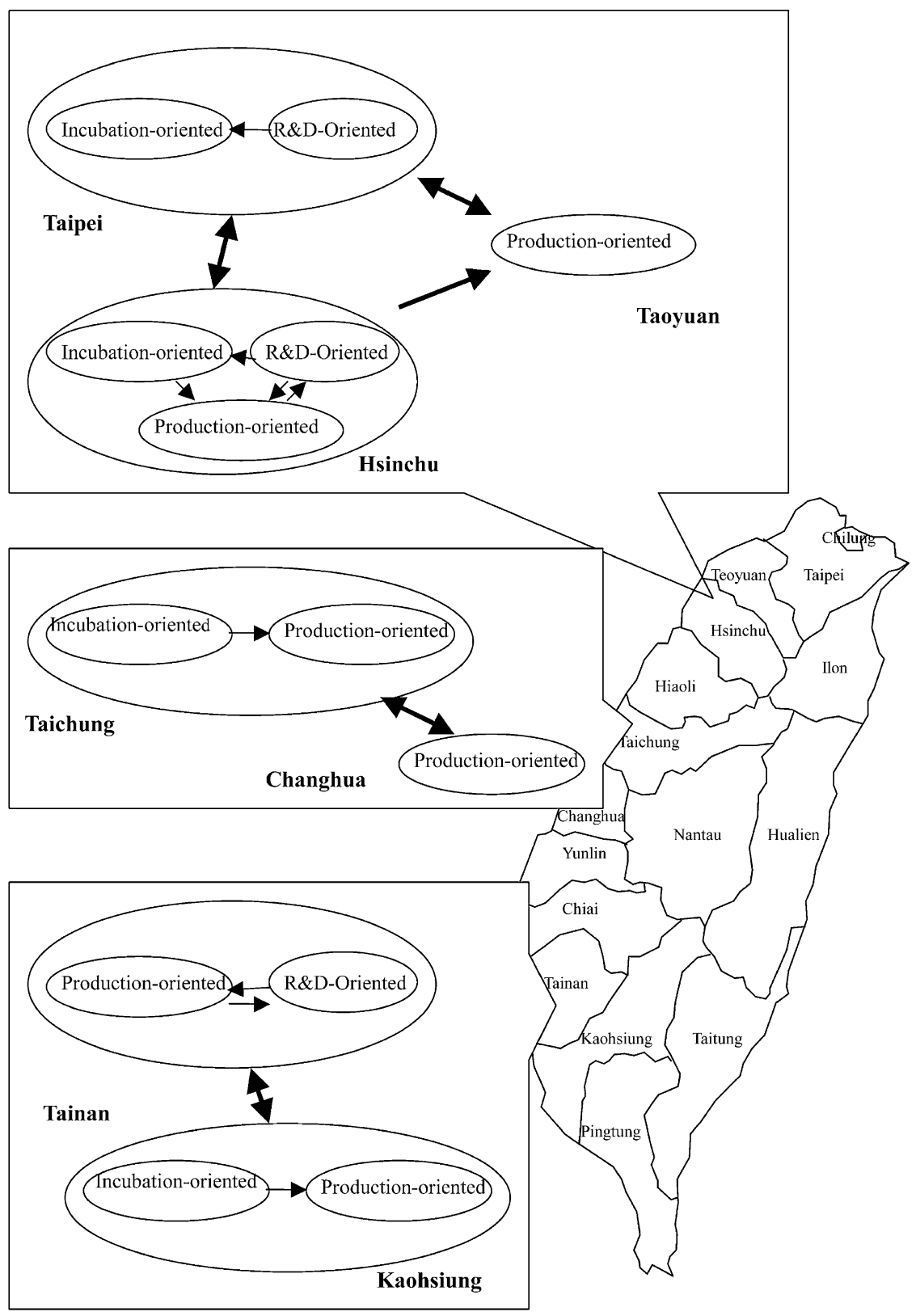

Fig. 1. Development strategies of Science Park in Taiwan. 


\subsection{Urban areas}

Owing to differences in developmental features among areas, the development process proceeds through various phases. Additionally, special characteristics lead to the park functions. The Taipei district is the political and economic center of Taiwan, with a high concentration of universities and research institutes, as well as $R \& D$ investments. However, large areas of land are difficult to find in highly developed districts. Consequently, the development of I\&IO and R\&DO parks in other areas should be emphasized.

In terms of land availability, employment rate, and average labor productivity, the Taoyuan area compares favorably with other urban areas, although it suffers from a relative weakness in terms of R\&D. However, since Taoyuan is close to Taipei, it is an ideal location for a production-oriented park. Such an arrangement would provide the Taipei area with a readily accessible base for the mass production of newly developed items. Such an arrangement would benefit both areas.

To complement the HSIP and government development policies, the Hsinchu area should focus on developing I\&IO and R\&DO parks. Besides fully exploiting the technology and $\mathrm{R} \& \mathrm{D}$ resources of this area, such an approach would promote the Hsinchu region as the center for technological research in Taiwan and enhance the international competitiveness of the area.

The Taichung and Tainan areas have relatively high quality living environment and maintain good R\&D support environment. Consequently, R\&D focused STPs could be developed in these two areas. Meanwhile, the Kaohsiung area is the second largest metropolitan district in Taiwan, and is the political and economic center of southern Taiwan. Based on the R\&D, commercial, skilled manpower, and educational strengths of Kaohsiung, integrated parks could be developed there focusing on incubation and production.

\subsection{Community areas}

Owing to limited developmental conditions, few development opportunities, low public investment, and population migration outflow, industrial development is limited in most other areas of Taiwan, besides the major urban mentioned above. Consequently, plans should be developed to connect these community areas with urban areas. Specifically, R\&DO or PO parks could be established in these areas, but the establishment of I\&IO parks would be less suitable. The development of PO parks would be suitable in Changhua and Pingtung, especially since these areas are located near Taichung and Kaohsiung, respectively. Besides offering production functions, these areas also could offer high quality residential and recreational facilities.

As for other areas facing sluggish development, the present developmental conditions are inadequate for establishing STPs. Consideration should first be given to creating
Table 1

Distribution of Science Parks and incubators

\begin{tabular}{llll}
\hline & Precinct & $\begin{array}{l}\text { Number of } \\
\text { Incubators }\end{array}$ & $\begin{array}{l}\text { Number of } \\
\text { Science Parks }\end{array}$ \\
\hline \multirow{2}{*}{ Northern region } & Chilung & 1 & - \\
& Ilan & 1 & - \\
& Taipei & 19 & - \\
& Taoyuan & 6 & - \\
Central region & Hsinchu & 4 & $2^{\text {a }}$ \\
& Hiaoli & 1 & - \\
& Taichung & 7 & 1 \\
Southern region & Changhua & 2 & - \\
& Yunlin & 3 & - \\
& Chiai & 2 & 1 \\
& Tainan & 3 & - \\
Eastern region & Kaohsiung & 7 & - \\
& Pingtung & 3 & - \\
\hline
\end{tabular}

Source: National Science Council and Ministry of Economic Affairs, Taiwan, the end of 2001.

a It includes Hsinchu and Chunan Science-based industrial park, however, Chunan park is located between Hsinchu and Hiaoli.

technology transfer centers, academic research institutes, or investing in public development to boost the technological level of industry and spur regional development. The establishment of further STPs could be considered in the future as appropriate.

As of 2001, Taiwan had four science-based industrial parks, namely Hsinchu (1980), Tainan (1995), Chunan (1998), and Taichung (2001). Besides these parks, Taiwan also had 62 innovation/incubation centers (Table 1 and Fig. 2), (47\%) located mostly around the Hsinchu and Chunan Parks.

\section{Methodology and data collection}

Since innovative knowledge is ambiguous, difficult to represent, and often discovered incidentally, its geographical and spatial transportation through communication is crucial. However, the marginal cost of transporting knowledge increases with distance, particularly knowledge that needs to be learned imperceptibly. That is, face-to-face interactions and frequent and recurring communications are important to companies seeking to utilize such difficult, ambiguous and uncertain innovative knowledge, acquire such knowledge themselves, and even attract agents including individuals or groups that have such knowledge. Therefore, this work hypothesizes that a particular innovative environment involves technological infrastructure establishments (including universities and research institutions), the implementation and facilitation of specific public policies by government, and agents such as companies. This environment produces self-sustaining 


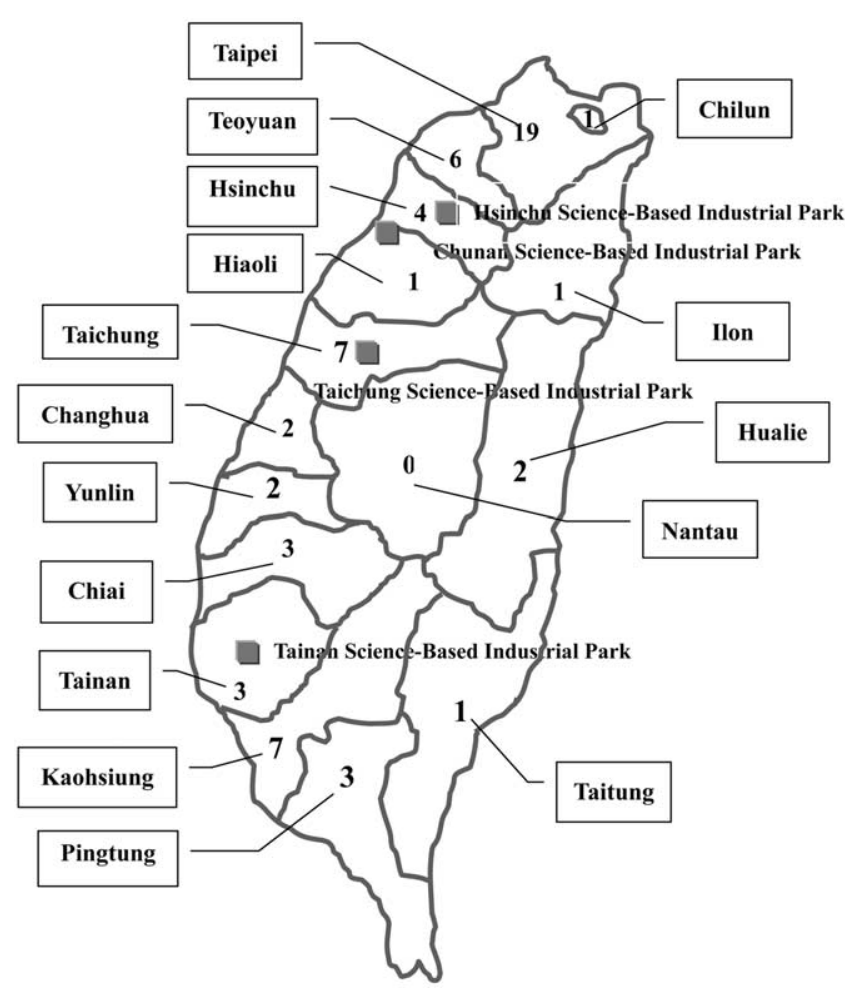

Fig. 2. The distribution of Science Parks and incubators.

spin-off effects through dynamic interactions among academic and research institutions and companies. Owing to the characteristics of innovative knowledge and spatial factors, this spin-off effect continues to accumulate in a particular area, but the speed of accumulation decreases with increasing distance, eliminating corporate advantages in competing for economic agents based on know-how related to new knowledge, technical professionals, knowledge and information, and so on. Consequently, the innovative milieu is formed through interactions among agents in an innovative environment. The purpose of companies in entering such a milieu is to acquire new technology flow and utilize the tangible technological infrastructure to maximize profits (Figs. 3 and 4).

To achieve the research goal, the methodology of this work is based on descriptive statistics, using indicators of innovative milieu. Data sources include governmental statistics and empirical survey data gathered by case studies. Although some case studies and government data failed to provide timely and appropriate information, they provide a good analytical basis for future research. This investigation used two major sources of data:

\subsection{Empirical data on the characteristics of innovation cluster formation}

These characteristics help companies to enhance their competitiveness. Because ITRI has been central in the technological development of Hsinchu and its interaction with surrounding areas, this work utilized the findings of the ITRI technology development projects and the outcomes of innovative incubators developed by ITRI. This investigation used indicators such as number of new companies formed, R\&D capital investment, technological workforce size and number of patents to analyze the local innovative production network and the formation of innovation cluster. This work also utilized some statistical data collected by ITRI and HSIP.

\subsection{Surveys and interviews}

This work also conducted surveys and interviews with technological professionals in HSIP and project managers of academic or research institutions located near HSIP. These

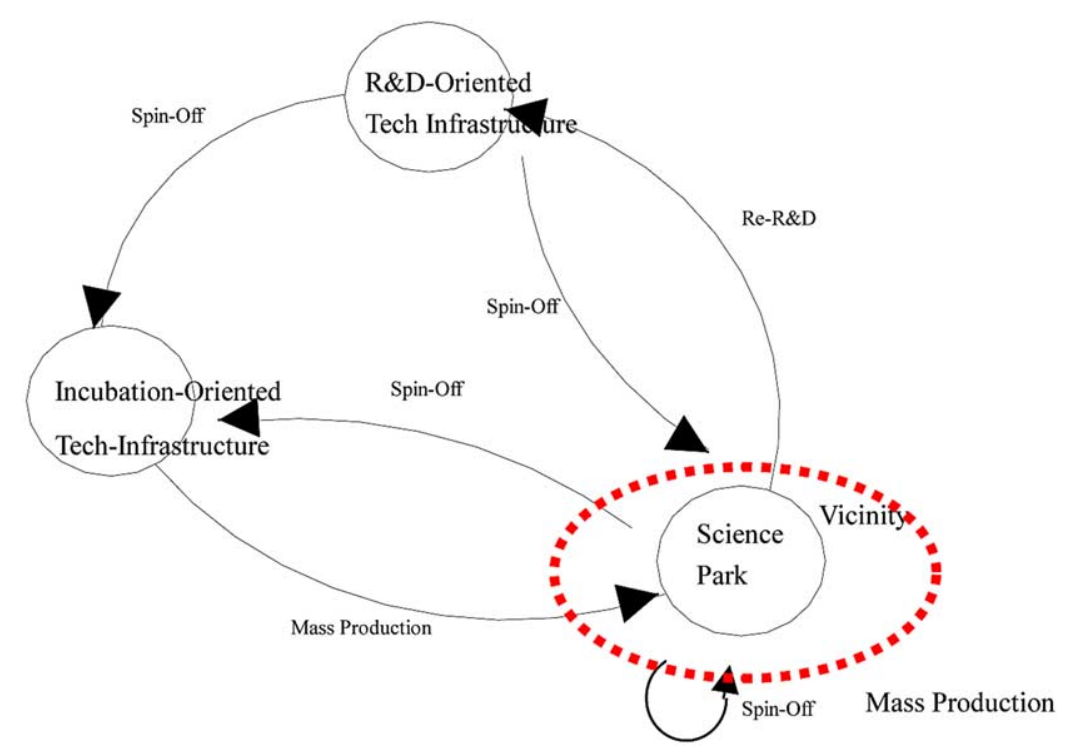

Fig. 3. Dynamics structure of innovation cluster. 


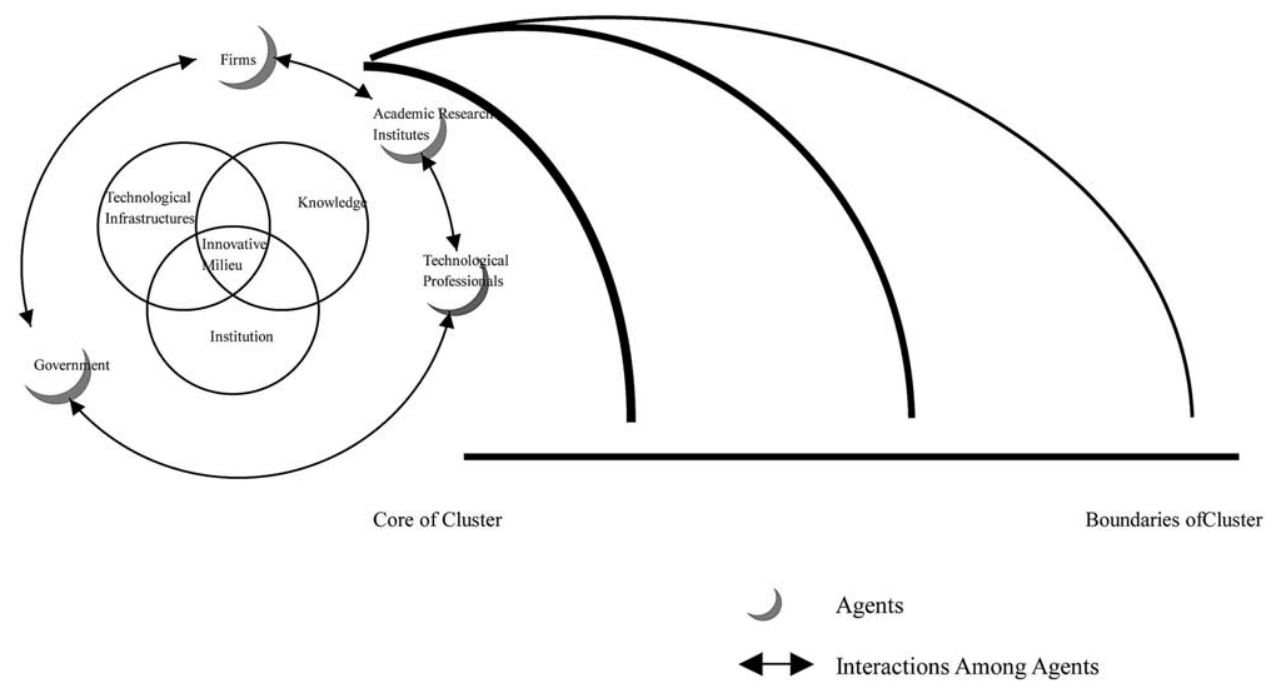

Fig. 4. Conceptual diagram of the structure of innovation cluster.

surveys and interviews aimed at enhancing understanding of the culture of high-tech social groups and institutions. ${ }^{2}$ The survey collected 268 valid samples during early 2001 and in the middle of 2001. Most of the subjects (45\%) worked in the integrated circuits industry, followed by computers and peripherals $(28 \%)$, telecommunications $(20 \%)$, and opticelectronics $(7 \%)$.

\section{Characteristics of innovation clusters in and around HISP}

New developments in globalization and communications technology have prompted developed countries to focus their competitive strategies on improving innovation. This shift also increased the value of knowledge-based economic activities. Knowledge-based economic activities or innovative activities generally cluster in areas with a rich base of scientific knowledge related to specific industries (Baptista, 1996), which is why companies capable of applying new knowledge in production and commercialization are focused in just a few areas of the world. Proximity helps to generate and transfer knowledge more effectively, and thus new knowledge-based activities tend to cluster in specific geographic localities (Audretsch, 1998). Accordingly, the Taiwanese government first created ITRI in 1973, and then established the HISP near ITRI in 1980.

After 20 years of development, HSIP currently comprises about 300 companies, with a total annual production of US\$ 20,330 million. ${ }^{3}$ HSIP has grown significantly, especially in

\footnotetext{
${ }^{2}$ In the early stage of the investigation, surveys were sent out to the subjects. After the surveys were returned, according to the answers on interview preference, interviews were conducted with subjects who were willing to be interviewed. The investigation conducted completed face-toface interviews with a total of 72 people.

3 According to the HSIP administration, there were 302 companies with an annual production of US\$20,330 million and a total of 105,782 employees in HSIP at the end of 2001.
}

the last 10 years. Annual production has increased 10-fold during the past 10 years, the number of companies has increased $150 \%$, and the number of employees has tripled. Because the presence of 300 companies at the HSIP was very attractive to technical workers, the quality of the labor force in the HSIP has improved considerably. Growth of employees with college degrees or better was $46 \%$ from 1997 to 1999 , compared to a $21 \%$ increase in the total number of employees. The area around HSIP also changed significantly. For example, the nearby and very accessible Hukou industrial zone originally was focused on traditional industries such as the ceramics, glass, beverage and chemical industries. However, by the end of 1999 , electronics related industries had grown to represent $30 \%$ of the total number of industries in Hukou. Out of these electronics related industries in Hukou, $40 \%$ involved semiconductor companies. Furthermore, the Taiwan Highway No.1 Corridor (excluding the Chunan Science Park) is located south of HISP and between Hsian-Shan and To-Fen Interchange, and this highway has also become an attractive location for high-tech companies because of its accessibility and low cost land (Fig. 5). Science Parks or companies located in the corridor created by this road include the Kuan-Yen Science Park, Kin-Yen Electronics, and so on. The force behind this prosperous development comes not only from the Park, but also from ITRI, which is essential to the technological infrastructure of the region.

\subsection{Formation of spin-off innovative companies}

ITRI is a non-profit research and development institution with a focus on applied technology research and scientific technology services. In 2000, ITRI had 6000 employees and 12 research units. During the creation of the Park, ITRI provided the greatest support to the HSIP, particularly when HSIP began to focus on semiconductor 


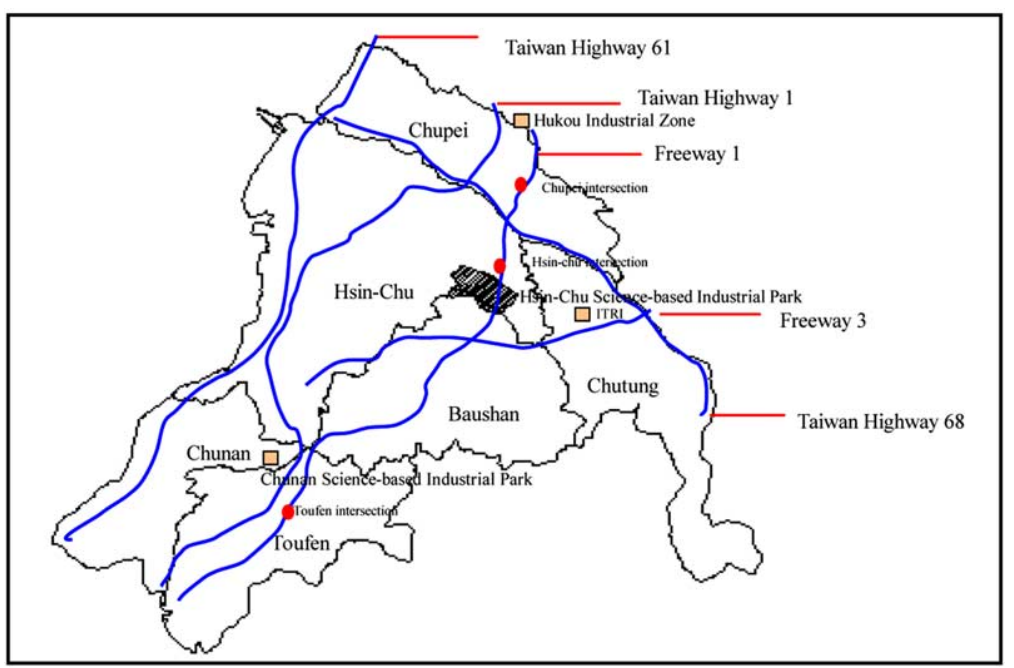

Fig. 5. Hsinchu district: location and major infrastructure and urban characteristics.

and computer/peripheral industries. ${ }^{4}$ Notably, the electronics and telecommunication departments in ITRI are the major sources of spin-offs. The electronics department of ITRI had 374 employees in 1980, the year after HSIP was created. By 1990, the number of employees in the electronics department of ITRI quadrupled to 1509, while the number of companies in HSIP has grown eightfold. Fifteen percent of the companies that moved to HSIP during 1987 through 1989 were created by the spin-off effect of R\&D technology professionals in ITRI. ${ }^{5}$ Furthermore, during the rapid growth of the Park in the 1990s, $25 \%$ of the 171 new companies established in HSIP were created by the spin-off effect originating from this technological infrastructure (ITRI), including the 10 companies created by the business incubator established by ITRI in 1997 (Fig. 6).

Approximately one-quarter of the innovative companies created by the R\&D technological professionals of ITRI from 1981 through 1999 chose to locate in the Park, while the remainder chose to locate near the Park and ITRI. During the same period, R\&D technological professionals continuously spun-off their knowledge to companies located within or outside the Park. Moreover, as noted earlier, besides the existing 12 research units, ITRI created a business incubator in 1997 to foster new innovative companies. This business incubator had successfully created 21 innovative companies by the end of 2000. Forty-eight percentage of these companies chose to locate in the Park,

\footnotetext{
4 According to the HSIP administration, the annual production of integrated circuits and computers and peripherals by the end of 2001 are US\$ 11,556 million and US\$ 4602 million, which amounted to 55\% and $31 \%$ of the total annual production of the HSIP, respectively.

5 Including several better-known semiconductor companies such as Taiwan Semiconductors, Macronix International Co., Ltd., Winbond Electronics Corp., Taiwan Fiber Optics, and so on. Taiwan Semiconductors was created under the leadership of the ITRI President Chun-Mo Chung and a team of almost 70 integrated circuits R\&D professionals.
}

while $24 \%$ chose to locate in the vicinity of ITRI and the Park (as revealed in Fig. 6).

Over the years, the outcomes of ITRI technology development projects, relying on technology transfer and spin-offs, have directly or indirectly led to the creation of numerous innovative companies. Among these companies, many were created directly by spin-offs of technology, facilities or professionals of technology development projects. Some were invested and created by companies that participated in the technology development projects or companies that benefited from technology transfers. Furthermore, some were created by employees of ITRI. All these different innovative companies share one characteristic in common, namely, their management teams and technology all originate from specialized science technology projects.

\section{2. $R \& D$ expenditure, technology transfer and patents granted}

The cost of communications has reduced significantly in the present era of globalization and communication technology. However, because of the ambiguity and uncertainty of new knowledge, high-tech companies still depend on the face-to-face interactions facilitated by spatial

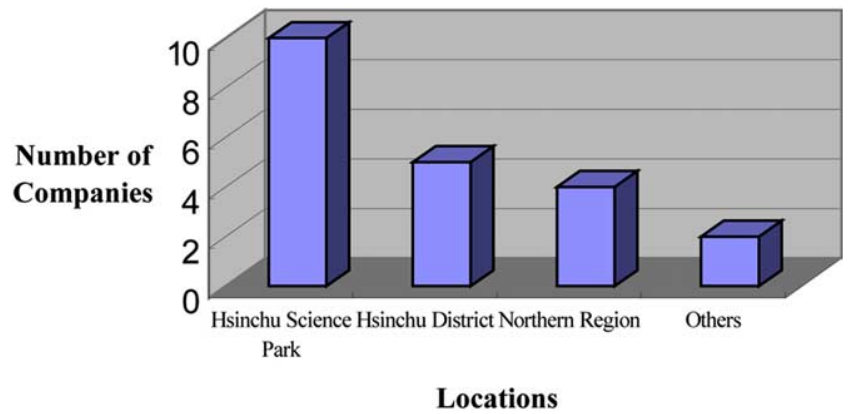

Fig. 6. Locations of companies created by the ITRI business incubator. 
Table 2

R\&D capital input and approved patents

\begin{tabular}{|c|c|c|c|c|c|}
\hline Year & $\begin{array}{l}\text { Number of approved } \\
\text { patents in the HSIP }\end{array}$ & $\begin{array}{l}\text { Number of approved } \\
\text { patents in the nation }\end{array}$ & $\begin{array}{l}\text { R\&D capital in the HSIP } \\
\text { (by US\$ million) }\end{array}$ & $\begin{array}{l}\text { R\&D capital in Hsinchu district } \\
\text { (by US\$ million) }\end{array}$ & $\begin{array}{l}\text { National R\&D capital of all } \\
\text { manufacturing industries } \\
\text { (by US\$ million) }\end{array}$ \\
\hline 1990 & - & 22601 & 107 & 191 & 1217 \\
\hline 1991 & - & 27281 & 131 & - & 1269 \\
\hline 1992 & - & 21264 & 139 & 210 & 1454 \\
\hline 1993 & - & 22317 & 197 & 302 & 1773 \\
\hline 1995 & 766 & 29707 & 393 & 518 & 2193 \\
\hline 1996 & 997 & 29469 & 557 & - & 2428 \\
\hline 1997 & 1582 & 29356 & 735 & 907 & 2931 \\
\hline 1998 & 1692 & 25051 & 1010 & 1206 & 3385 \\
\hline 1999 & 2536 & 29144 & 1108 & 1302 & 3666 \\
\hline
\end{tabular}

Source: (1) Indicators of Science and Technology, Taiwan. (2) Technology Agency and Statistics Agency, Ministry of Economic Affairs, Taiwan.

clustering, and thus location remains important. Furthermore, the more R\&D is inputted into a clustered space, the faster new technologies and products can be released, the greater the profits from new technologies and products will be, and the more innovative outcomes will be stimulated. Examining total corporate spending on R\&D in the Hsinchu district in 1990 reveals that only 56\% came from companies located in HSIP. However, by 1998, this figure had increased to 84\% (Table 2). From 1990 through 1999 , the R\&D capital input of companies in HSIP increased 10-fold, exceeding not only that of companies in the wider Hsinchu district, but also exceeding the national average. This phenomenon was further evidenced in the dominance of information technology hardware of publicly traded semiconductor companies in the US software patents registered by Taiwanese companies, revealed in the statistics collected by the Industrial Development Bureau, Taiwan Ministry of Economic Affairs. Among the top $10^{6}$ companies and institutions, $70 \%$ were located in Hsinchu district.

R\&D capital input level further stimulates competition among companies or agents, as demonstrated clearly by the number of patents generated by companies in HSIP and ITRI. From 1994 through 1999, the number of overseas approved patents originating from Taiwanese companies grew $53 \%$. During the same period, the number of overseas patent approvals originating from Taiwanese companies located in HSIP increased 6.7-folds. Additionally, while only $2 \%$ of the total number of patents in Taiwan were owned by HSIP companies in 1994, this number grew to $10 \%$ by 1999 . Moreover, $12 \%$ of the total overseas approved patents owned

\footnotetext{
${ }^{6}$ According to the Industrial Development Bureau, Taiwan Ministry of Economic Affairs, from 1995 through 1999, the 10 companies that had the highest numbers of approved US patents include: United Microelectronics Corp. (24), ITRI (24), Macronix International Co., Ltd. (18), Taiwan Semiconductors (13), Winbond Electronics Corp. (13), Primax electronics Ltd. (8), National Science Council, Taiwan (7), Hotelk Semiconductor Inc. (7), Behavior Tech Computer Corp. (6) and Inventec Corp. (6), and so on.
}

by Taiwanese companies are controlled by HSIP companies. ${ }^{7}$ These data demonstrate that, in terms of competition for the timely release of new products and procedures, information and technology flow in the cluster drives innovation.

Likewise, in 1994 only $22 \%$ of the capital involved in technology transfer in the information electronics industries occurred in the Hsinchu district. However, by 1996, $42 \%$ occurred in the Hsinchu district (Table 3). This increase shows that the clustering of related or similar industries in a particular geographic location benefits the accelerated release of new discoveries or the acquisition of market share information. Consequently, the speed and intensity of innovation increases. The cluster of R\&D capital input not only increases innovation energy, but also boosts profits from industrial activities that rely on new knowledge. For example, $30 \%$ of the 78 publicly traded electronic companies in the Hsinchu district had average EPS exceeding 3 from 1996 through 1999, and only 11\% recorded deficits.

\subsection{Local innovation network}

Successful innovative companies created by the ITRI business incubator include new branch units established by existing companies spin-offs established by R\&D professionals at existing companies and research institutions. Both professional spin-offs of ITRI and innovative companies incubated by ITRI tend to prefer locations in or around the Park. Because HSIP and ITRI have different functions, these two institutions share an intricate relationship characterized by compensation and demand. That is, the technological infrastructure spins-off or transfers professionals or technology to HSIP, and the Park demands technological innovations and R\&D from the technological infrastructure. This relationship forms a science park system

\footnotetext{
7 In 1999, there were a total of 11,092 overseas approved patents in Taiwan. Out of this number, 1276 were owned by companies located in the Park (Source: 2000 Indicators of Science and Technology, Taiwan).
} 
Table 3

ITRI technology transfer statistics

\begin{tabular}{|c|c|c|c|c|c|c|c|}
\hline \multirow[t]{2}{*}{ Year } & & \multicolumn{2}{|l|}{ Information electronics } & \multicolumn{2}{|l|}{ Metal mechanics } & \multicolumn{2}{|l|}{ Chemical engineering } \\
\hline & & Number of companies & US\$ (thousand) & Number of companies & US\$ (thousand) & Number of companies & US\$ (thousand) \\
\hline \multirow[t]{2}{*}{1994} & Hsinchu district & 49 & 1056 & 8 & 62 & 2 & 19 \\
\hline & Total in Taiwan & 223 & 4845 & 136 & 724 & 61 & 393 \\
\hline \multirow[t]{2}{*}{1995} & Hsinchu district & 28 & 1001 & 6 & 187 & 2 & 4 \\
\hline & Total in Taiwan & 130 & 3132 & 138 & 1091 & 76 & 867 \\
\hline & Total in Taiwan & 201 & 6401 & 131 & 1290 & 98 & 1021 \\
\hline \multirow[t]{2}{*}{1997} & Hsinchu district & 44 & 1352 & 8 & 181 & 4 & 25 \\
\hline & Total in Taiwan & 189 & 3257 & 109 & 950 & 112 & 1576 \\
\hline \multirow[t]{2}{*}{1998} & Hsinchu district & 79 & 3281 & 9 & 93 & 10 & 132 \\
\hline & Total in Taiwan & 278 & 6935 & 124 & 1331 & 148 & 3043 \\
\hline \multirow[t]{2}{*}{1999} & Hsinchu district & 64 & 1837 & 9 & 144 & 5 & 76 \\
\hline & Total in Taiwan & 243 & 6438 & 68 & 1223 & 102 & 1953 \\
\hline 2000 & Total in Taiwan & 249 & 11137 & 103 & 2752 & 42 & 1252 \\
\hline
\end{tabular}

Source: Department of Technology Services, ITRI.

containing an innovation system ( $\mathrm{Hu}, 1991,2001 ; \mathrm{Hu}$ and Lin, 2003). Furthermore, although communication costs have fallen significantly owing to globalization and improved communications technology, face-to-face interaction remains essential to high-tech innovative activities, particularly given that new innovative knowledge is ambiguous, uncertain, difficult to symbolize, and complex. Such face-to-face interactions can allow knowledge to be accumulated and changed slightly in a specific geographic location. Consequently, while clustering is essential to innovation, location also remains very important.

There are several potential phenomena in the specific geographic location described above. First, agents with new knowledge in research institutions or companies may create their own companies focused on mass production. Second, to acquire new technology or improve products and procedures, existing companies may commission academic/research institutions to conduct $R \& D$ or export $R \& D$ teams to work in these institutions. Third, the innovative companies developed by all types of business incubators can establish factories and initiate mass production in a particular locality. These phenomena reveal that interactions occur mainly between companies and ITRI, or between companies and academic research institutions, and enable functions such as R\&D, mass production and incubation and the gradual creation of an innovative production network in a locality (Fig. 7). This network is the foundation of local industrial innovation. That is, innovative companies seek to gain control of the latest technology or product information, recruit important or outstanding R\&D or technological professionals, acquire elements of state-of-the-art or key technologies, and aggregate in a specific locality.

However, the question arises of whether the interactions among companies within this network structure are as intense as those between companies and academic research institutions. Moreover, if the two types of interactions are equally intense, then the question of whether the interactions are sufficient to enable the formation of a local

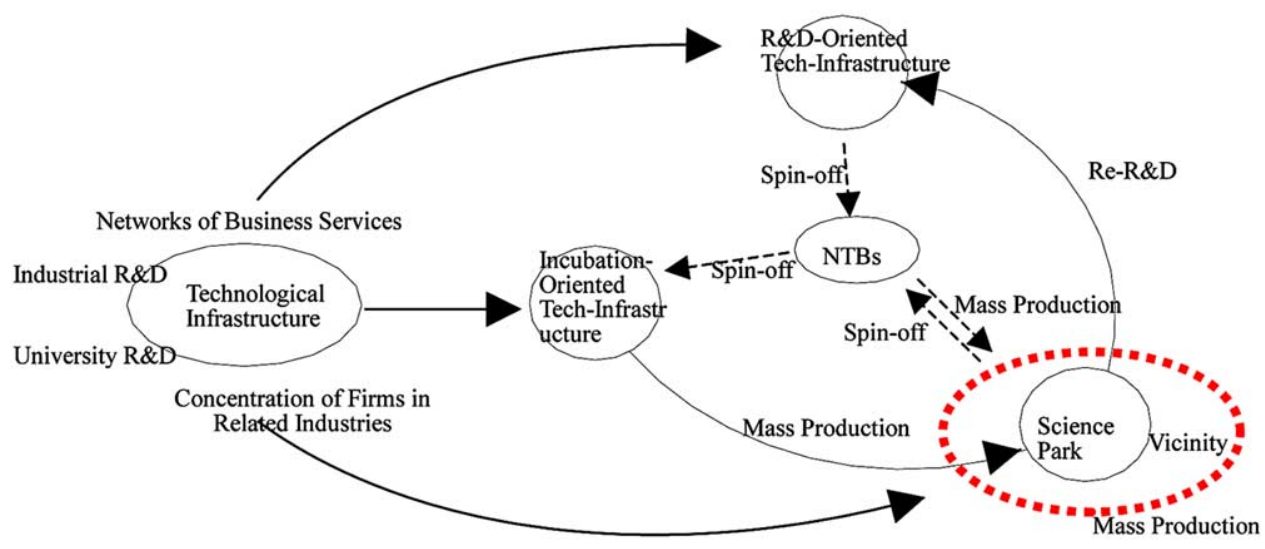

Fig. 7. Concept of a local innovation and production network. 
production network, a technological community, and so on arises. This work investigates the formation of such a learning network using the results of surveys and interviews with R\&D and technological professionals in HSIP.

\section{Survey results}

The hypothesis of this investigation is "when companies cluster in a specific locality, their interactions are characterized by competition for specific resources within that locality". Specifically, this work focuses on the formation of innovative milieu owing to such interactions. First, companies compete for technological professionals, and even professionals in other areas. Thus, in terms of channel of information, $26 \%$ of first-time employees ${ }^{8}$ in HSIP acquired employment information from relatives or friends who were already working in HSIP. Among those surveyed $40 \%$ originally lived in Hsinchu district, and just $20 \%$ came from areas outside Hsinchu district. Once these professionals entered HSIP, 38\% acquired further employment opportunity information from relatives and friends working in HSIP, and 22\% acquired such information from social gatherings in HSIP or within companies. Consequently, the professional employment market formed by the cluster of similar and/or related companies in the Hsinchu district is utilized by companies to discover new knowledge teams or opportunities.

In terms of the acquisition of knowledge from the working environment, nearly $75 \%$ of $\mathrm{R} \& \mathrm{D}$ or technological professionals resolved problems through formal channels established for this purpose by their companies, while $25 \%$ utilized informal channels, generally seeking help from friends working inside or outside HSIP in similar industries but different companies. Among professionals who utilized informal channels for problem resolution, $50 \%$ verified their information by referring to multiple sources. Overall, this approach resembles learning networks (Bessant and Francis, 1999). However, different companies in the similar industries are in competition, making it dangerous to rely on a single information source. As for the key knowledge, such knowledge is difficult to acquire locally, even through informal channels. Consequently, 20\% of the surveyed R\&D or technological professionals extended their informal networks overseas, mainly to Silicon Valley ${ }^{9}$, and relied on former classmates or friends for information.

This work also speculated that the local production network is the foundation of innovation. However, the survey results reveal that collaborations among companies on $\mathrm{R} \& \mathrm{D}$ or product design represented less than $30 \%$, and

\footnotetext{
${ }^{8}$ The other sources of employment included human resources companies $(30 \%)$ and newspapers $(23 \%)$.

${ }^{9}$ Compared with Saxenian and Hsu 2001, p.919).
}

mostly were involved companies involved in the same industry but at different levels. That is, companies at the same level of the same industry are in competition. Consequently, such companies gather in the Hsinchu district to acquire elements such as information and agents, and to better understand their competitors. Companies mainly form international coalitions, while establishing horizontal collaboration or vertical integration relationships with local companies, thus forming both competitive and collaborative interactions. This type of interaction establishes excellent competitive advantages for companies located in HSIP and its vicinity. ${ }^{10}$ Therefore, the interaction network among local companies is a key contributor to specific innovations. Furthermore, although companies in and around HSIP have certain supply production coalitions, ${ }^{11}$ local economic linkages represent a weak, short-term, non-systematic production network. That is, the companies in and around HSIP ultimately will be driven to other regions such as China under the pressure of price competition and demand. ${ }^{12}$ This indicates that the competitive and collaborative relationships among the companies do not help them to establish deep local roots. This structure differs from the notion of an innovative production network embedded in a locality, as conceived by most research on this topic. However, the idea that an innovative production network encourages innovative companies to cluster in a locality is verified. This phenomenon confirms that HSIP is basically a production-oriented science park. R\&D activities in HSIP thus tend to involve enhancing existing products or technologies rather than introducing new innovations (Table 4). Notably, these activities simply represent methods to prolong product life cycles through expeditious, frequent and gradual innovations and the international division of labor.

In terms of turnover of technological professionals, such turnover was highest among engineering technological professionals in production departments, followed by

\footnotetext{
10 The milieu created by the Park further prompted companies to cluster. For example, the IC Design company located near Taiwan Semiconductors commissions Taiwan Semiconductors to produce their IC. Once the production is completed, they can perform tests on the IC immediately. Because the machines in Taiwan Semiconductors are in operation for $24 \mathrm{~h}$ a day, as soon as the IC passes the tests, it can be forwarded immediately to the packaging factory, which is also in $24 \mathrm{~h}$ a day operation. Any mistakes in the process can be immediately corrected through feedback. Such connected production process, when compared to many large international firms' procedures of commissioning South Korea companies to produce IC and packaging IC in Singapore or Malaysia, the IC development process in Taiwan is at least 15 days shorter (Source: senior technological professionals of Taiwan Semiconductor, 2001). Because of the short product life cycle and the pressure of new product development, the compression in schedule creates competitive advantages for IC industries in Taiwan.

${ }^{11}$ Some companies located in the Park and companies outside the Park belong to the same corporation group, such as Acer Incorporated, United Microelectronics Corp., Microtek International Incorporated, and so on.

12 Particularly industries that are obsolete or labor intensive, such as manufacturers of 8-inch IC, monitor, mouse, keyboard, and so on.
} 
Table 4

Characteristics of Research in HSIP

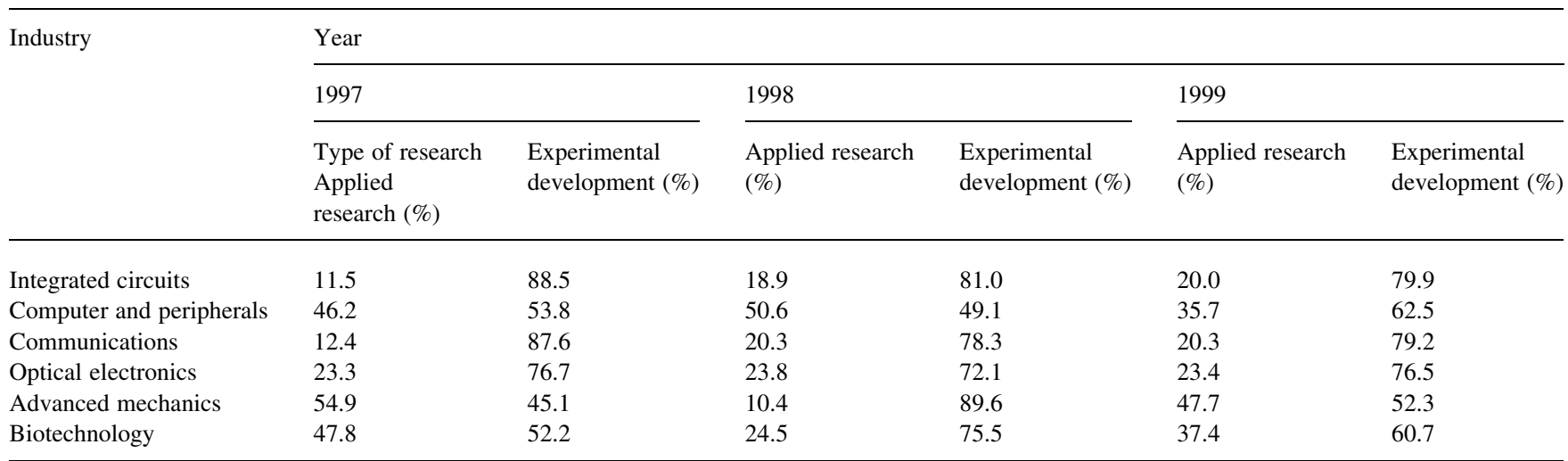

Source: HSIP administration. Note: Applied research refers to the actual application of a discovered new knowledge, including inventions of new methods or new usage, or focusing on a particular application goal or objective. Experimental development refers to the development of new product, improvements of procedures, and methods to enhance production efficiency.

technological professionals in service and R\&D departments. Around 53\% of interviewees planned to change jobs in 2-3 years, and $29 \%$ planned to change jobs in $1-2$ years. The reasons for job change included low current salaries and bonuses $(56 \%)$, followed by a non-stimulating work environment $(15 \%)$ and a desire to join a team working with innovative technology (9\%). Therefore, the most popular career path in HSIP was to work for well-known companies (70\%). Only $11 \%$ of interviewees were willing to work for start-up companies working on innovative projects. This indicates that the majority of $\mathrm{R} \& \mathrm{D}$ and technological professionals follow conventional career paths, competing to work for bigger, more mature and better-known companies, and lack the risk-taking mentality of seeking to participate in the early life cycle of innovative products. This mentality dominates in the culture of the technological community through proximity and synergy elements. Such a culture is also evident in the emphasis of the R\&D activities of HSIP companies on improving production procedures or enhancing production efficiency (as listed in Table 4). This phenomenon displays a very different mindset to that of technology professionals in Silicon Valley, who compete to undertake new challenges in developing progressive technology. Consequently, Silicon Valley leads HSIP in various key technologies and advanced products (Saxenian, 1994).

Furthermore, agents with new economic knowledge do not change jobs as easily as expected. One reason for this phenomenon is that their current companies can still match their expected values, therefore they stay with these companies. Also, when the current companies are unable to match their expected values, the team with the new knowledge or technology will move to another companies, or alternatively create a new start-up to realize the ambitions of the team members. In the implementation process of specialized science technology projects conducted by the ITRI, because R\&D activities are commissioned by companies or R\&D workers are exported to ITRI by companies to conduct R\&D activities, the local spin-off phenomenon is particularly obvious. Only by working or experimenting with $R \& D$ or innovative agents can the recipients of technology transfer really learn a new knowledge or technology. This process of technology transfer also leads to spin-offs of new knowledge or technology. Therefore, companies operating in such locations find it easier to gain control of new technology or product information, recruit important or outstanding $\mathrm{R} \& \mathrm{D}$ technological professionals, and acquire the latest or key technologies, thus further strengthening the accumulation of innovation.

Additionally, owing to the ambiguity and uncertainty of new knowledge, innovative activities of high-tech companies continue to be necessary to emphasize face-to-face interactions in spatial clustering, so that knowledge can be accumulated and slightly changed in a specific space. Among companies that collaborate in $\mathrm{R} \& \mathrm{D}$ or product design or nearly $30 \%$ of the total in HSIP, $55 \%$ maintained face-to-face interactions at a frequency of at least weekly twice. Since the life cycle of high-tech products is shortening, rapid problem resolution is essential for these companies. The interactions between two parties associated with the solution of advanced technology related problems grow significantly after a while, and begin to induce innovations and enhance the competitive advantages of a company compared to its competitors.

Because companies at the same level of the same industry are competitors, corporate collaboration mostly occurs among related industries, and a continuous system is lacking (Fig. 8). However, companies can attain temporary collaboration or support quickly, which can be attributed to an embedded local compatibility. Namely, when companies face market competition, spatial proximity and the normally unattached local technology community will adjust and reorganize resources flexibly. As Porter (1998) noted, the emphasis of companies to cluster in a locality is controlled 


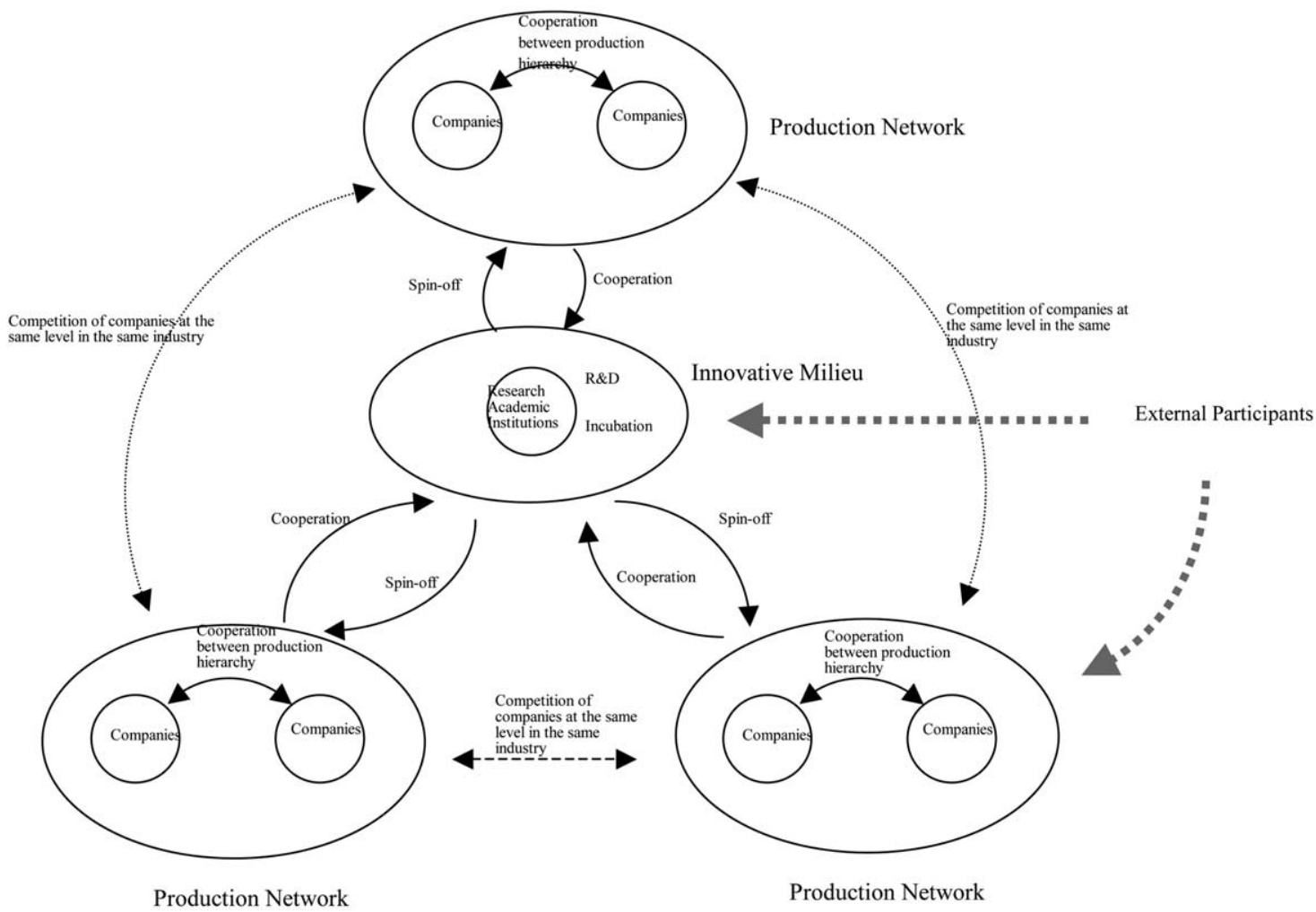

Fig. 8. Hsinchu district innovative production network.

by key resources and information. To develop competitive capital, companies clustered in an area must rely on human relationships, common interests, face-to-face interactions and identification with the local community. Therefore, in HSIP and other clusters of particular industries, over $60 \%$ of science and technological professionals in the technological workforce utilize informal social gatherings, such as reunions and book clubs, to maintain and expand their professional networks. Such channels can provide opportunities to discuss difficult problems, or share common experiences. Additionally, around $20 \%$ of science and technological professionals formed professional networks through seminars or conferences. Forty-four percentage of these gatherings were conducted irregularly, while $38 \%$ were conducted once or twice monthly. The frequency thus resembles that of informal channels used by science and technological professionals to acquire support or technology. This phenomenon indicates that the spontaneity and uncertainty of new knowledge in the innovative R\&D process led to occasional and non-continuous interactions and collaborations among technological professionals and companies.

The more agglomerated companies are, the more obvious are the opportunities for innovation. The capabilities and flexibility formed in a locality can help companies to acquire the resources they require. These required resources include interactions with suppliers in related industries, which can accelerate innovation and make products and services better match market demands. However, the soundness of a local business potential environment created by clustering will influence the ability of companies to achieve solid growth. Owing to overcrowding and the competitive effect created by clustering, similar to the growth of agglomeration, overcrowding is expected reduce the benefits of clustering. Likewise, any advanced technology will be replaced by a new innovative technology. When new industrial clusters emerge, existing industrial centers decline (Brezis and Krugman, 1993). Therefore, developing a clustering locality can influence the formation of production capabilities through the aggregation of innovative spin-off companies. Around $40 \%$ of technological professionals interviewed identified the ability of innovative spin-off companies with innovative energy to enhance local innovations during the clustering progress. That is, the spin-off of innovative companies means the emergence of new products, which stimulates innovation in local related industries or companies manufacturing similar products.

\section{Conclusions}

Less-developed countries always lack well-developed industrial clusters, and thus their regional or national 
economies can only compete globally by relying on cheap labor and natural resources (Porter, 1998). All industrial clusters have an agglomerative economic effect, but cluster location is important in industries that rely on new knowledge. Cluster locations require adequate technological infrastructure, mature innovative interactions within technological human resources and benefits that can compensate for diseconomy factors. The proximity among companies created by such clusters is essential to stimulate company learning, creating compatible knowledge spillover effects and establishing a positive feedback among various local agents.

Competition is the basis for forming a local innovative milieu. Although numerous studies have introduced notions of collective learning, sticky knowledge and learning processes, untraded dependencies, and even network formation, competition among new products and technologies remains essential to technology-based industrial competition. To be leaders in creating new products or introducing new technologies, companies must be located in an industrial cluster to compete for key resources. Such resources include anything that can help increase profits, including agents with new knowledge, technological professionals, information, and even potential partners (such as local companies or suppliers). Similarly, within the technological workforce centered on the industrial cluster, knowledgeable agents compete to work for companies that meet their requirements for an employer, and technological professionals compete for better employment opportunities. Consequently, most R\&D and technological professionals in the Hsinchu district follow the career path of competition to work for larger, more mature and more famous companies, and lack the risk-taking mentality required to participate in the preliminary stage of developing new knowledge. Owing to proximity and synergy, this trend is the norm in technological community culture.

Moreover, the majority of innovative companies created through spin-offs from local companies or the Institute of Industrial Technology Research (ITRI) chose to locate their mass production in the HSIP or Hsinchu district. Additionally, to utilize spatial proximity to exploit the competitive elements outlined above, these companies consider the transfer of local technological infrastructure, spin-offs of technological professionals, and equipment and resources for further R\&D. Business incubators recently established by academic or research institutions are also beneficial for enhancing local entrepreneurial environment. These phenomena benefit the further R\&D of existing companies or the R\&D incubation of innovative companies, thus establishing a local innovation network. Furthermore, to achieve the same goals while boosting market competitiveness, related industries and companies collaborate in the short-term. This type of cooperation is occasional rather than continuous, and thus represents a temporary collaborative production network (as shown in Fig. 8). Consequently, the innovation network formed in the Hsinchu district, focused on ITRI, further causes the aggregation of innovative companies and increases competition among new products and production procedures. However, owing to the obscure local production network and weak links within the local economy, companies are not embedded in the local economy. That is, the Hsinchu district cluster is based mainly on a combination of collaborative and competitive interactions. Although this pattern differs from that emphasizing collaboration and dependencies, as discussed in previous research, it is still a local innovative milieu.

\section{Acknowledgements}

The authors would like to thank the National Science Council of the Republic of China, Taiwan for financially supporting this research under contract no. NSC 92-2211-E216-012.

\section{References}

Acs, Z.J., Audretsch, D.B., 1988. Innovation in large and small firms: an empirical analysis. American Economic Review 78(4), 678-690.

Audretsch, D.B., 1998. Agglomeration and the location of innovative activity. Oxford Review of Economic Policy 14(2), 18-29.

Audretsch, D.B., Feldman, M.P., 1996. R\&D spillovers and the geography of innovation and production. American Economic Review 86(3), 630-645.

Baptista, R., 1996. Research round up: industrial clusters and technological innovation. Business Strategy Review 7(2), 59-64.

Bessant, J., Francis, D., 1999. Using learning networks to help improve manufacturing competitiveness. Technovation 19, 373-381.

Brezis, E. S., Krugman, P., 1993. Technology and the life cycle of cities. NBER Working Paper No.4561.

Camagni, R.P., 1995. Innovative milieu and European lagging regions. Papers in Regional Science 74(4), 317-340.

Feldman, M.P., 1994. The university and high-technology start-ups: the case of Johns Hopkins University and Baltimore. The Economic Development Quarterly 8(1), 67-76.

Freeman, C., 1991. Network of innovators: a synthesis of research issues. Research Policy 20, 499-514.

Glaeser, E.H.K., Scheinkman, J., Shleifer, A., 1992. Growth of cities. Journal of Political Economy 100, 1126-1152.

Hart, D., Simmie, J., 1997. Innovation, competition and the structure of local production networks. Local Economy Nov, 235-246.

Hsu, J.-Y., 1998. Toward a learning region? Industrial agglomeration and technological learning in Taipei-Hsinchu corridor. Geographical Research 29, 143-159.(in Chinese).

Hu, T.-S., 1991. Regional development strategies for Science Park in Taiwan. Master Thesis, Graduate School of Urban Planning, National Chun-Kung University (in Chinese).

$\mathrm{Hu}, \mathrm{T} . \mathrm{S} .$, 2001. Technological infrastructure industrial cluster and local innovative network: a Hsin-Chu case. Journal of Architecture and Planning 2(1), 27-42.Chung Hua University (in Chinese).

Hu, T.-S., Lin, C.-Y., 2004. Socioeconomic analysis of the Hsin-Chu technopolis evolution in Taiwan: 1980-2000. Asian Pacific Planning Review (forthcoming). 
Kung, H.-F., 1999. A study of spin-off phenomenon of high-tech industries using Hsinchu district as a case study. Research Project of the National Science Council, Taiwan (in Chinese).

Lin, C.-Y., 1997. Technopolis development: an assessment of the Hsinchu experience. International Planning Studies 2(2), 257-272.

Maillat, D., 1998. Innovation milieux and new generations of regional policies. Entrepreneurship and Regional Development 10, 1-16.

Malmberg, A., 1997. Industrial geography: location and learning. Progress in Human Geography 21(4), 573-582.

Markusen, A., 1996. Sticky places in slippery space: a typology of industrial districts. Economic Geography 72, 293-313.

Porter, M.E., 1990. The Competitive Advantage of Nations, Macmillan, London.

Porter, M.E., 1998. Clusters and Competition, Harvard Business School Publishing, Boston.

Ritsila, J.J., 1999. Regional differences in environments for enterprises Entrepreneurship and Regional Development 11(3), 187-202.

Saxenian, A., 1994. Regional Advantage: Culture and Competition in Silicon Valley and Route 128, Harvard, Boston.

Saxenian, A., Hsu, J.Y., 2001. The Silicon Valley-Hsinchu connection: technical communities and industrial upgrading. Industrial and Corporate Change 10(4), 893-920.

Storper, M., 1995. The resurgence of regional economics ten years later: the region as a nexus of untraded interdependencies. European Urban and Regional Studies 2, 191-221.
Yang, Y.R., 1999. Regional restructure in the global economy: the case study of Hsinchu new industrial space and regional development. Cities and Design 7/8, 93-131.(In Chinese).

Tai-Shan Hu, Lecturer, Department of Architecture and Urban Planning, Chung-Hua University, Hsinchu. Ph.D. candidate, Graduate Institute of Urban Planning, National Taipei University, Taipei. His main research interests are in the field of technology-based industries development, Science Parks, and regional technology-based industrial policy. His dissertation deals with the establishment of the well-developed entrepreneurial environment in Taiwan.

Chien-Yuan Lin, Professor, Graduate Institute of Building and Planning, National Taiwan University, Taipei. Dr Lin's teaching and research activities focus on the areas of conveyance and land use, analytic methods for planning, environmental risk management, land development and management, industrial location theory, and high-tech industrial development. He has consulted for several public and private organizations, also he is a technology consulting committee of The Office of The President of Taiwan, and the President of Taiwan Institute of Urban Planning.

Su-Li Chang, Master, Graduate Institute of Technology Management, Chung-Hua University, Hsinchu, Taiwan. She has focused on the related issues of technology and financial management. 